\title{
PENDIDIKAN MULTIKULTURAL DI SEKOLAH DASAR (Sebuah Studi Pustaka)
}

\author{
Nur Latifah', Arita Marini ${ }^{2}$, Arifin Maksum³ ${ }^{3}$ \\ nurlatifah1v4@gmail.com ${ }^{1}$, aritamarini@unj.ac.id ${ }^{2}$, amaksum@unj.ac.id ${ }^{3}$ \\ PGSD, FKIP, Universitas Muhammadiyah Tangerang ${ }^{1}$ \\ Pendidikan Dasar, Pascasarjana Universitas Negri Jakarta ${ }^{2}$ \\ Pendidikan Dasar, Pascasarjana Universitas Negri Jakarta ${ }^{3}$
}

\begin{abstract}
Abstrak: Tujuan penelitian ini untuk mengelaborasi pelaksanaan pendidikan multikultural di sekolah dasar berdasarkan landasan teori. Peneliti dalam penelitian ini mengunakan metode study literature atau penelitian kepustakaan. Pengumpulan data di lakukan melalui metode dokumentasi. Teknik analisis data yang digunakan berupa analisis isi. Pembacaan pustaka secara berulang dan pengecekan antar pustaka dilakukan agar menjaga ketepatan pembahasan dan mencegah kesalahan informasi dalam analisis data. Tujuan penelitian ini adalah untuk menyusun landasan teoritis dan pelaksanaan pendidikan multicultural di sekolah dasar. Hasil penelitian ini adalah terelaborasinya landasan teori dan pelaksanaan pendidikan multicultural di sekolah dasar secara menyeluruh yang meliputi: 1) pengertian pendidikan multikultural, 2) komponen pendidikan multikultural, 3) program pelaksanaan pendidikan multikultural, 4) manfaat pendidikan multicultural di sekolah dasar, 5) Hasil pendidikan multicultural di sekolah dasar.
\end{abstract}

Kata kunci: pendidikan multicultural, sekolah dasar.

\section{MULTICULTURAL EDUCATION IN ELEMENTARY SCHOOLS (A literature review)}

\begin{abstract}
The purpose of this study was to elaborate the implementation of multicultural education in schools based on theoretical foundations. Researchers in this study used literature study or library research methods. The data collection used is the documentation method. The data analysis technique used is content analysis. Reading the literature repeatedly and checking between libraries is carried out in order to monitor the accuracy of discussion and prevention of misinformation in data analysis. The purpose of this study is to develop a theoretical foundation and implementation of multicultural education in primary schools. The results of this study are the elaboration of the theoretical basis and implementation of multicultural education in elementary schools which includes: 1) The meaning of multicultural education, 2) components of
\end{abstract}


Nur Latifah, Arita Marini, Arifin Maksum. Pendidikan Multukultural di Sekolah Dasar multicultural education, 3) multicultural education implementation programs, 4) benefits of multicultural education in elementary schools, 5) Multicultural education results in elementary school.

Keywords: multicultural education, elementary school.

\section{PENDAHULUAN}

Indonesia memiliki jumlah pendudukan yang sangat banyak. Menurut Kepala BKKBN DR dr Sugiri Syarif, MPA dalam majalah tempo mengatakan bahwa di akhir tahun 2011 pendudukan Indonesia berjumlah 241 juta jiwa dan akan mencapai 300 juta pada tahun 2015. Berdasarkan data dari BPS (Biro Pusat Statistik) sebanyak 1.128 suku bangsa yang diketahui di Indonesia yang terdata. Sementara seluruh penduduk dengan beragam suku bangsa itu berdiam di sekitar 13.466 pulau. Data tersebut berdasarkan riset Timnas PNR(Pembakuan Nama Rupabumi) yang dimasukkan ke dalam laporan secara resmi ke dunia internasional dan telah disertai koordinat global positioning system (GPS) seperti yang dikemukakan oleh Kepala BIG (Badan Informasi Geopasial) Asep Karsidi pada Kamis 17 Oktober 2013 di Metro TV News.

Sebagai negara yang memiliki jumlah penduduk yang banyak, negara Indonesia merupakan salah satu negara yang multikultural terbesar di dunia, yang memiliki suku bangsa dengan budaya dan bahasanya yang beragam, kepercayaan, keadaan sosialekonomi, keanekaragaman agama dan serta gender (Suryana, 2015). Dengan situasi kemajemukan tersebut, maka dirasakan perlu dikembangkannya sikap toleransi bagi siswa sekolah dasar yang baru mengenal situasu keberagaman dan social yang berbeda tersebut.perilaku menghargai dapat terbentuk dan muncul di antara keberagaman sehingga dapat mewujudkan ketentraman, kenyamanan dalam tatanan kehidupan masyarakat (Farikhatin et al., 2016). Pada akhirnya tumbuhnya toleransi pada diri siswa dapat menunjang tercapainya masyarakat multikultural yang rukun dan harmonis.

Penelitian ini bertujuan untuk mengetahui sejauh mana pendididkan multicultural di terapkan di sekolah dasar dengan mengelaborasi landasan teori dan pelaksanaan pendidikan multicultural di sekolah dasar secara utuh yang meliputi: pengertian pendidikan multikultural, komponen pendidikan multikultural, program pelaksanaan pendidikan multikultural, manfaat pendidikan multicultural di sekolah dasar, dan hasil pendidikan multicultural pada sekolah dasar. 
Nur Latifah, Arita Marini, Arifin Maksum. Pendidikan Multukultural di Sekolah Dasar METODE

Peneliti dalam penelitian ini mengunakan metode study literature atau penelitian kepustakaan. Pengumpulan data yang digunakan yaitu metode dokumentasi. Beberapa referensi yang tidak akan lepas dari literatur-literatur ilmiah Studi pustaka berkaitan dengan kajian teoritis. Dalam penelitian kepustakaan langkah-langkah tersebut meliputi (Loe, 2017)1) bagian pendahuluan, 2) bagian utama, 3) kesimpulan.

Sumber data penelitian ini diperoleh dari literatur-literatur yang relevan seperti buku, artikel ilmiah atau jurnal yang terkait dengan topik yang dipilih. Teknik pengumpulan data yang digunakan dalam metode study literature atau penelitian kepustakaan ini yaitu mendapatkan data penelitian berdasarkan hal-hal atau variabel dalam bentuk artikel, jurnal, catatan, buku dan sebagainya (Santosa, 2015).

Teknik analisis data yang digunakan berupa analisis isi. Pembacaan pustaka secara berulang dan pengecekan antar pustaka dilakukan agar menjaga hasil penelitian secara tepat dan meminimalisir kesalahan di karnakan kekurangan dari peneliti ( terhindarnya dari kesalaham penyampaian informasi). Penelitian ini di laporkan dengan menyusun hasil penemuan berdasarkan prinsip kemudahan dan kesederhanaan. Hal ini mengingat peneliti memiliki keterbatasan kemampuan yang belum mampu melakukan kajian pustaka secara mendalam dan lebih detail. Selain itu, kesederhanaan dan kemudahan dalam penyampaian hasil dibuat agar mempermudah pembaca dalam memahami inti isi mengenai Pendidikan Multikultural di sekolah dasar.

\section{HASIL}

\section{Pengertian Pendidikan Multikultural}

Keberagaman masyarakat Indonesia sebagai masyarakat majemuk yang memiliki keberagaman suku, budaya, adat istiadah dan perbedaan agama, ras, kebudayaan dan lain sebagainya menjadikan masyarakat Indonesia yang multikulrural. Hal ini dapat di jadikan tantanagan dalam mempersatukan Indonesia menjadi masyarakat yang kuat dalam perbedaan dan keberagamani. Hal tersebut dapat dilakukan dengan mengajarkan pendidikan multikultural sedini mungkin yang ditanamkan kepada siswa dalam pembelajaran. Seorang guru bertanggung jawab dalam memberikan pendidikan terhadap siswanya dalam melihat perbedaan yang terjadi dalam kehidupan mereka sehari-hari. 
Nur Latifah, Arita Marini, Arifin Maksum. Pendidikan Multukultural di Sekolah Dasar Sebagai sarana alternatif pemecahan konflik penting adanya pendidikan multikultural di Indonesia. Pendidikan multikultural memiliki peran yang penting untuk meminimalisasi dan mencegah terjadinya konflik. Dengan melalui pendidikan multikultural peserta didik diharapkan tidak meninggalkan akar budaya bangsanyanya, dan pendidikan multikultural sangat relevan digunakan untuk negara yang demokrasi pada masa sekarang ini. Dengan demikian walau menghadapi arus globalisasi para peserta didik itu tidak akan terbawa pengaruh yang negatif dari segi kepribadian bangsa. Pada akhirnya pendidikan multikultural ini dapat mengantarkan masyarakat Indonesia menuju masyarakat yang multikultural, yang mampu hidup secara rukun dan harmonis diantara beragam perbedaan yang dihadapinya dalam kehidupan sehari-hari. Hal tersebut perlu didukung oleh adanya penerapan konsep demokrasi, keadilan dan hukum, penghargaan terhadap HAM, berdasarkan nilai-nilai idelologi bangsa.

Shaw berpendapat bahwa pendidikan multicultural adalah pendidikan yang bertujuan untuk menjembatani perbedaan rasial dan menghilangkan ketidaksetaraan antara berbagai kelompok sosial masyarakat (Shen, 2019). Membentuk sikap sosial siswa melalui kegiatan pembelajaran dengan memanfaatkan keberagaman dalam pergaulan tanpa memandang perbedaan budaya, ras, kondisi jasmaniah, jenis kelamin maupun status sosial masing-masing siswa (Pratiwi, Masfuah, \& Rondli, 2018).

Mahiri mengatakan pendidikan multikultural merupakan pemahaman tentang isu-isu seputar siswa imigran dan cara yang lebih baik untuk melayani kebutuhan belajar dan sosial mereka (Mahiri, 2017). Berdasarkan pendapat pendidikan Multikultural adalah pembelajaran yang mengajarkan pesertadidik tentang makna dan sikap dari setiap keberagaman.

\section{Komponen Pendidikan Multikultural,}

Untuk menerapkan pendidikan multikultural dengan tingkat keberhasilan, semua variable sekolah saling terkait dan memiliki peran dan tanggung jawab masing-masing karna sekolah sebagai sistem sosial. Pemikiran sekolah sebagai sistem sosial menunjukkan bahwa kita harus merumuskan dan memulai strategi perubahan yang mereformasi total lingkungan sekolah untuk menerapkan pendidikan multikultural (Jun, 2016). 
Nur Latifah, Arita Marini, Arifin Maksum. Pendidikan Multukultural di Sekolah Dasar

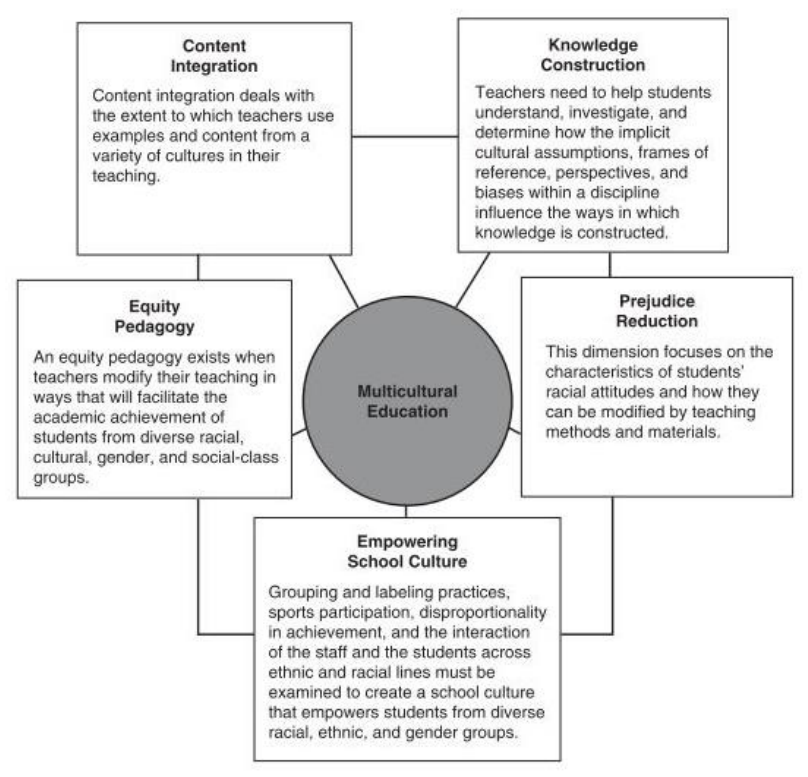

\section{Gambar 1. Dimensi Pendidikan Multikultur menurut James A Banks}

Sejauh mana guru menggunakan contoh dan konten dari berbagai kultur dan kelompok untuk menggambarkan konsep, prinsip, generalisasi, dan teori utama dalam bidang subjek atau disiplin mereka hal ini disebut sebagai integrasi konten. Ada juga peluang untuk mengintegrasikan konten multikultural ke dalam matematika dan sains. Namun, peluangnya tidak sebanyak yang ada dalam studi sosial (Ambarudin, 2016), seni bahasa, dan musik.

Proses konstruksi pengetahuan berkaitan dengan sejauh mana guru memiliki tanggung jawab utama. Dan dalam penelitian ini juga terlihat bahwa pendidikan guru dan sikap positif guru terhadap pendidikan multikultural memiliki peran penting untuk hidup dalam rasa toleransi menjadi damai dan penuh rasa saling menghormati untuk menerima semua identitas dengan kekayaan budaya mereka tanpa takut akan pemisahan (Y1lmaz, 2016). Pengurangan prasangka menggambarkan pelajaran dan kegiatan yang digunakan guru untuk membantu siswa mengembangkan sikap positif terhadap berbagai kelompok ras, etnis, dan budaya.

Pedagogi Ekuitas Guru dalam setiap disiplin ilmu dapat menentukan sejauh mana mereka mencerminkan masalah dan kekhawatiran multikultura dan menganalisis prosedur dan gaya pengajaran mereka. Struktur Sosial yang memberdayakan dimensi 
Nur Latifah, Arita Marini, Arifin Maksum. Pendidikan Multukultural di Sekolah Dasar penting lain dari pendidikan multikultural serta budaya sekolah terkait organisasi sekolah yang mempromosikan kesetaraan gender, ras, dan kelas sosial.

\section{Program Pelaksanaan Pendidikan Multikultural}

Penelitian yang dilakukan oleh retnasari mengemukakan hasil dari perogram pelaksanaan pendidikan multikulrural dengan membangun pemahaman keberagaman pada lingkungan sekolah melalaui paradigma keberagaman inklusi, mata pelajaran PPKn berbasis multikultur yang tersusun dalam program intrakulikuler, program kokurikuler, dan kedisiplinan seorang pengajar (Latifah, 2018) hal ini menunjukan bahwa program pelaksanaan pendidikan multicultural di lakukan dengan mengintergasikan mata pelajaran di dalamnnya.

Pada pelaksanaan kegiatan mengajarkan pendidikan multikultural juga harus diajarkan di ruang kelas, sekolah, dan agar membagun kesadaran kritis siswa dan guru tentang apa yang terjadi saat ini (Au, 2017). Hal ini dapan menumbuhkan nilai-nilai positive kepada pesertadidik. Guru dan Siswa memiliki peran (Kirom, 2017) sebagai demonstrator, pengelola kelas, mediator dan evaluator sedangkan siswa sebagai subject dalam pendidikan multicultural. Guru yang sudah memiliki pengalaman dalam perogram pengembanagan dalam pengajaran pendidikan multikulturan akan lebih berhasil dalam mengajar pendidikan multikultural (Jun, 2016).

\section{Manfaat Pendidikan Multicultural di Sekolah Dasar}

Terdapat beberapa manfaat dari pemdidikan multicultural diantarannya yaitu mencegah sikap radikalisme di era globalisasi (Latifah, 2018). Tujuan utama pendidikan multikultural dapat menjadikan generasi muda sebagai agen peredam konflik antar golongan (SARA) yang biasa melibatkan gerakan radikalisme yang kerap terjadi di Indonesia. Mampu menjadi teladan yang mampu menerima perbedaan dengan penuh toleransi menjadikan tugas guru sebagai pendidik, hal tersebut harus diimbangi dengan pemahaman konsep multikultur secara komperhensif. Karena sudah dibekali sikap untuk saling toleran, menghormati, tulus terhadap keanekaragaman yang ada di masyarakat Indonesia. Sehingga, perbedaan suku, adat, ras, dan agama tidak menjadi celah untuk gerakan radikalisme 
Nur Latifah, Arita Marini, Arifin Maksum. Pendidikan Multukultural di Sekolah Dasar Pendidikan multukultural dapat terintegrasi dengan mata pelajaran agama seperti pendidikan islam multicultural dapat menjadikan pemahaman keislaman dalam masyarakat muslim yang berubah terhadap perbedaan. Adapun sikap yang perlu dirubah atau di perbaiki adalah yang ada perlu diubah menjadi universalisme, dengan harapan dapat melahirkan generasi yang siap hidup dalam toleran (tasamuh) dan wacana multikultiralisme sehingga tidak adannya sikap exclusivis yang dapat menjadikan peserta diidk yang ekstrim terhadap pemahamnnyadan kurang mampu memiliki rasa toleransi serta perbedaan antar pesertadidik yang lain (Akbarjono, 2018).

\section{Hasil Pendidikan Multicultural di Sekolah Dasar.}

Berdasarkan Danel dalam penelitian pendiidkan multicultural sekolah dasar di wilayah 3T menunjukan hasil bahwa pendidikan multicultural dapat terbentuk dengan cara pembiasaan untuk tidak berprilaku dan berfikir membeda-bedakan, dengan memahami dan menghargai persepsi orang lain, menumbuhkan kesetaraan serta rasa kesamaan serta keadilan social. Sedangkan penelitian Lisa (Retnasari \& Hidayat, 2018) strategi pendekatan aditif dengan peran serta pendidik pada proses pengintegrasian nilai-nilai multikultural dalam pembelajaran di sekolah dasar dapat dilakukan dengan pelaksanaanya pendidikan multikultural

Di perlukan beberapa aspek dalam mengajarkan pendidikan multikultural yaitu membiasakan pesertadidik untuk tidak memperlakukan orang lain secara diskriminasi dan membedakan, serta memahami dan menghargai pendapat oranglain, layanan pendidikan adalah ruang dinamis di mana sekolah menjadi tempat untuk mertukar fikiran, pendapat, dengan menghindari penyimpangan yairu rasisme atau menjadikan sati pemahaman yang tidak dapat dijadikan sebagai rasa toleransi.. Menumbuhkan rasa simpati dan empati dengan membangun kultur respect for others sesuai budaya masyarakat tiap-tiap daerah. Serta dapat menumbuhkan rasa kesetaraan dan keadilan sosial, yakni memberikan akses dan kesempatan yang sama kepada semua budaya, etnis dan agama di sekolah.

\section{PEMBAHASAN}

Dalam proses mengkaji kepustakaan pendidikan multikultutal di sekolah dasar ini ditemukan beberapa hal utama dalam pengajaran pendiidikan multicultural yaitu: 
Nur Latifah, Arita Marini, Arifin Maksum. Pendidikan Multukultural di Sekolah Dasar

1. Pengajaran sejak dini (Dike, 2017)terkait pendidikan multicultural karna sikap multicultural perlu di tanamkan dan di tumbuhkan sejak dini.

2. Mengintegrasikan bebagai mata pelajaran (Watkins, Lean, \& Noble, 2016)dengan pendidikan multicultural merupakan cara efektif untuk menumbuhkan sikap di setiap pengajaran yang diajarkan.

3. Stategi dan pendekatan berfariasi sanagat di perlukan dalam pendidikan multicultural, hal ini di pahami agar pesertadidik dapat dengan mudah memahami esensi dari pendidikan multicultural. Sebagai contoh negri Thailand menerapkan program pendidikan bilingual yang terintegrasi dengan pendidikan multicultural (Arphattananon, 2018). Sedangkan di Korea menerapkan pengajaran multicultural yang di sesuaikan dengan geografis (Shen, 2019).

4. Peran guru sebagai pengajar merupakan ujung tombak keberhasilan dalam pendidikan multicultural (Susiloningsih, 2020) karna pesertadidik akan mudah mencontoh tauladan dan perilaku sesuai dengan tidakan yang di tunjukan oleh guru, hal ini sesuai dengan (Gorski, 2016) pengembanagn professional guru melalui kegiatan pengembangan pendidikan multicultural dapat menjadikan pembelajaran lebih bermakna.

Selain hal utaman yang di temukan dalam pendidikan multicultural, di temukan pula hambatan dalam pendidikan multukultural di antaranya masih minimnnya pelatihan guru tentang pengajaran berbasis pendidikan multicultural (Pratiwi, Masfuah, \& Rondli, 2018), lingkungan sekolah yang plularisme sehingga menimbulkan sikap kurangnnya toleransi, pengitegrasian pendidikan multicultural kurang tampak di setiap mata pelajaran.

\section{SIMPULAN}

Pendidikan multikultural di sekolah dasar pada dasarnya bersifat sistemik dan holistik artinnya perlu dikembangkan. Pendidikan multikultural pada Sekolah Dasar dikemas berdasarkan budaya dan karakter bangsa. Pendidikan multikultural bertujuan membentuk sikap, prilaku dan pemikiran lebih komperhensif pada peserta didik dalam memandang keberagaman, sehingga mampu memumbuhkan toleransi. Pendidikan multicultural dapat menjadikan peserta didik paham akan keberagaman dan dapat meumbuhkan rasa. 
Nur Latifah, Arita Marini, Arifin Maksum. Pendidikan Multukultural di Sekolah Dasar Pelaksanaanya pendidikan multikultural di Sekolah Dasar dapat dilakukan melalui berbagai strategi dan pendekatan serta mengintergrasikannya kedalam setiap mata pelajaran, perlu adanya peran serta pendidik pada proses pengintegrasian nilainilai multikultural dalam kegiatan pembelajaran. Selain itu pendidik harus mampu dalam menguasai ilmu pengetahuan khususnya pendidikan multikultur dan mampu memilihh materi sesuai dalam pembelajaran di Sekolah Dasar.

\section{DAFTAR RUJUKAN}

Akbarjono, A. (2018). Eksistensi Guru Dalam Penanaman Nilai Pendidikan Islam Multikultural Di Era Milenial. At-Ta'lim : Media Informasi Pendidikan Islam, 17(2), 171. https://doi.org/10.29300/attalim.v17i2.1408

Arphattananon, T. (2018). Multicultural education in Thailand. Intercultural Education, 29(2), 149-162. https://doi.org/10.1080/14675986.2018.1430020

$\mathrm{Au}$, W. (2017). When Multicultural Education Is Not Enough. Multicultural Perspectives, 19(3), 147-150. https://doi.org/10.1080/15210960.2017.1331741

Dike, D. (2017). Pendidikan Multikultural Sekolah Dasar di Wilayah 3T. Sereal Untuk, $3(1), 277-287$.

Farikhatin, A., Suryaningsih, A., Wibawa, D. B. S. A. E. A., Sari, E. Y., Mutakhim, I. R. I., Ma'rifah, I., ... Suwandi. (2016). Mengelola Keragaman di Sekolah. In Mengelola keragaman di sekolah: Gagasan dan pengalaman guru.

Gorski, P. C. (2016). Making better multicultural and social justice teacher educators: a qualitative analysis of the professional learning and support needs of multicultural teacher education faculty. Multicultural Education Review, 8(3), 139-159. https://doi.org/10.1080/2005615X.2016.1164378

Jun, E. J. (2016). Multicultural education course put into practice. Multicultural Education Review, 8(2), 83-98. https://doi.org/10.1080/2005615X.2016.1184921

Kirom, A. (2017). Peran Guru Dan Peserta Didik Dalam Proses Pembelajaran Berbasis Multikultural. Al Murabbi, 3(1), 69-80. Retrieved from http://jurnal.yudharta.ac.id/v2/index.php/pai/article/view/893

Latifah, N. (2018). BAHASA INDONESIA. In Mengembangkan Kompetensi Pendidik dalam Menghadapi Era Disrupsi" Kerjasama PGSD - POR UMS. 
Nur Latifah, Arita Marini, Arifin Maksum. Pendidikan Multukultural di Sekolah Dasar Loe, S. (2017). Mencerahkan bakat Menulis (Tilarasma, ed.). Jakarta: PT. Gramedia Pustaka Utama.

Mahiri, J. (2017). Introduction: multicultural education 2.0. Multicultural Education Review, 9(3), 143-144. https://doi.org/10.1080/2005615X.2017.1346555

Pratiwi, I. A., Masfuah, S., \& Rondli, W. S. (2018). Pendidikan Multikultural Berbantuan Metode Pictorial Riddle Untuk Meningkatkan Karakter Kreatif dan Bersahabat Siswa Kelas 3 Sekolah Dasar. Scholaria: Jurnal Pendidikan Dan Kebudayaan, 8(2), 109-119. https://doi.org/10.24246/j.js.2018.v8.i2.p109-119

Retnasari, L., \& Hidayat, M. T. (2018). Pendidikan multikultural dengan pendekatan aditif di sekolah dasar. 28(1), 16-21.

Santosa, P. (2015). Metodologi Penelitian Sastra: Paradigma, Proposal, Pelaporan, dan Penerapan.

Shen, S. (2019). Teaching 'multiculturally': geography as a basis for multicultural education in Korea. Multicultural Education Review, 11(1), 37-58. https://doi.org/10.1080/2005615X.2019.1567092

Suryana, Y. dan R. (2015). Pendidikan Multikultural "Satu Upaya Penguatan jati Diri bangsa. Bandung: CV Pustaka Setia.

Susiloningsih, W. (2020). Pendidikan Multikultural di Sekolah Dasar "Kajian Analitis Dalam Prespektif Filsafat.” Didaktis: Jurnal Pendidikan Dan Ilmu Pengetahuan, 20(1), 82-88. https://doi.org/10.30651/didaktis.v20i1.4488

Watkins, M., Lean, G., \& Noble, G. (2016). Multicultural education: the state of play from an Australian perspective. Race Ethnicity and Education, 19(1), 46-66. https://doi.org/10.1080/13613324.2015.1013929

Y1lmaz, F. (2016). Multiculturalism and multicultural education: A case study of teacher candidates' perceptions. Cogent Education, 3(1), 1-13. https://doi.org/10.1080/2331186X.2016.1172394 